\title{
LEPROSY IN MALTA
}

\section{INTRODUC'TION}

Sir Walter Johnson, during his visit of medical inspection in Malta, investigated among other matters the question of leprosy. On his return he consulted me as to what steps should be taken, and expressed a desire that I should visit Malta if an opportunity occurred. Later, Dr. Naudi of the Nigerian Medical Service seconded for special leprosy work in Malta, invited me to visit the island on my way to the East in March, 1938. My visit was also welcomed by Dr. Bernard, the Chief Medical Officer. Later I was present at a conference called together by the LieutenantGovernor to discuss what steps should be taken. The following is a short report which I drew up as a result of my visit.

Leprosy should be regarded as a disease, just as tuberculosis is a disease. At present it is looked upon with fear and abhorrence quite out of proportion to its danger. Though an infectious disease, it is much less fatal and less easily acquired than tuberculosis. Not infrequently the disproportionate abhorrence with which leprosy is regarded leads to its dissemination, as the leper conceals his condition and thus, before he is recognised as a source of danger, mixes with his family and the public unchecked for many years. There is reason to believe that this is the case in Malta, as cases, when admitted to hospital, have already reached an advanced and contagious stage.

\section{The Leper Hospital}

I visited this institution with Dr. Naudi and I have the following comments to make:-

(a) Site. The Hospital is situated on a very fine site. The buildings are ample and spacious, and there is abundant ground not only for the buildings, but also for cultivation and other activities of the patients.

(b) Staff. I was particularly struck with the large number of the staff in proportion to the number of patients. Their number is larger than I found in leper hospitals in other countries. It has been usual in most of the leper institutions with which I am acquainted for most of the work to be done by the patients themselves, under the direction of a comparatively small staff.

(c) The Patients. Of these, there are 56 males and 29 females -85 in all.* Some of these are cripples or are confined to

\footnotetext{
* Non-infectious patients are released from isolation, under the present law
} 
bed with acute complications, but the majority are able-bodied persons capable of doing at least a moderate day's work. And yet they do little to help themselves or their fellow-patients, and there appears to be little attempt at cultivation of the available land. As it is now generally acknowledged that occupation therapy is the most important factor in the treatment of leprosy, I asked for the reason of their inactivity, and was informed that the patients are lazy and unwilling to work. This is the more anomalous as most of them are cultivators and accustomed to work, and I understand that 200 a year is expended on encouraging cultivation.

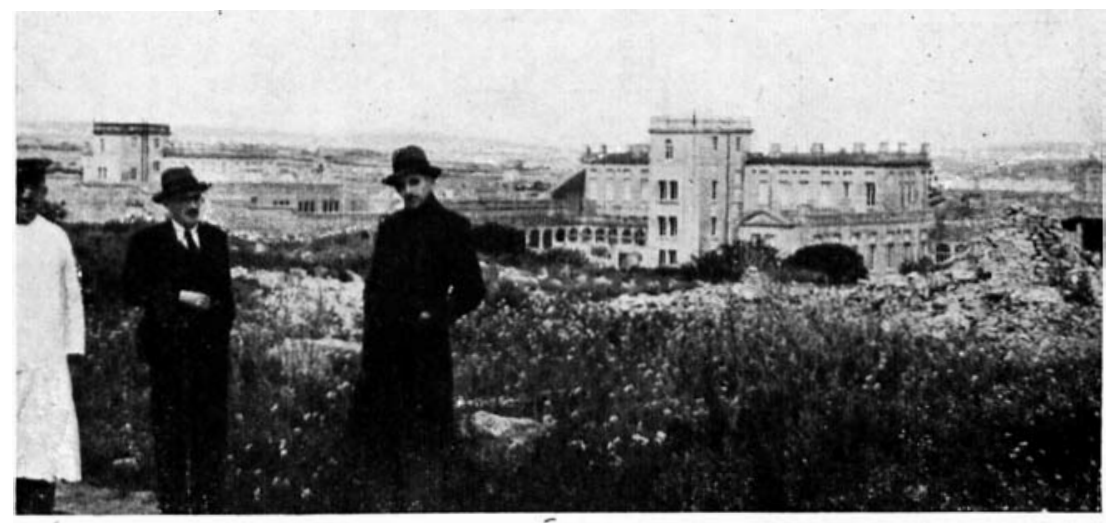

To the right is the Malta Leprosy Hospital, the poor-house to the left. In the foreground is Dr. Naudi (right) and the doctor in charge.

(d) Compulsion. There seems to be little doubt that the patients bear in their minds a grudge against the authority which has compulsorily segregated them, and that their reaction on account of their feeling of being wronged is one of non-co-operation. This is a natural reaction and one which is found wherever compulsion is used. To counteract it I understand that the patients are dealt with very generously, and that their diet per head per day amounts to six shillings, as compared with two shillings for the paupers in the neighbouring building.

Experience however shows here, as elsewhere, that such generosity tends to increase rather than diminish the feeling of grievance. It confirms the sens $n$ of what the patient regards consciously or unconsciously as infringement of his rights of liberty. 
The feeling of grievance is not confined to the patient compulsorily detained in the leper asylum, but is sometimes shared by the patient's relatives and, possibly, by his neighbours. The result is non-co-operation in the community, and concealment of infectious cases of leprosy as long as they are not too conspicuous and can be hidden, while further as the co-operation of the patient is lacking effective treatment becomes impossible. in my opinion, at least 75 per cent of leprosy treatment is of a general nature, and has as its basis a cheerful co-operating patient, active and fully occupied in mind and body; and special treatment is much more effective and better tolerated when these are secured.

On the other side of the picture is the need for isolation of the infectious patient from the community, and especially from contact with children. If isolation could be effectively carried out without rigid compulsion, then there would be every chance of its giving better results through winning the co-operation of patients and the public.

\section{SUGikst IONS}

I suggest that three objectives should be aimed at:- to make the hospital more attractive; to relax the present rigidity of the law and practice regarding segregation; to carry out an educative campaign, along with a leprosy survey and arrangements for treatment in the endemic areas. These three objectives should be carried out simultaneously.

(a) Making the Hospital more attractive. It is questionable if this will require increased expenditure. It must be clearly kept in mind that what makes the hospital unattractive at present is not lack of good buildings, good food, staff and land. But it is the feeling of grievance referred to above. As this is due to rigid segregation the first step in making the hospital attractive must be a change of the law and practice regarding segregation. How this may be affected I shall discuss later.

The second step in making the hospital attractive is, I suggest, the appointment of a suitable lay worker who will befriend the patients and organise their time and daily life. Such a man must be one with the missionary spirit, a man of sympathy, understanding and strong personality. He must be a whole-time worker who has been well trained in leprosy work. His duties would be to organise occupational therapy in the form of cultivation, industries, games, etc., and otherwise brighten the lives of the patients and help to keep them usefully and happily employed.*

Note. * I understand that this suggestion has not been approved on account of cost, but that it will be reconsidered. 
Suggestions already put forward by Dr. Naudi for improving the diet of the patients should be of great value, and secure better nutrition and better value for the money spent.

At the same time, in the case of bread winners, provision should be secured, either directly or indirectly, that dependents are helped when necessary. $\dagger$

(b) Modification of the Segregation Lan's and Practice. These are at present, in my opinion, too rigid and, as stated above, tend to defeat the end for which they were instituted by leading to concealment of cases of leprosy long after they have reached the infectious stage.

The methods used for the control of leprosy vary in different countries according to local conditions. In England, though there are several infectious cases at large who have acquired the disease in the tropics, the infection, with the exception of some three known cases, has not spread, and compulsory segregation and notification are not in force.

In Paris recently it was found that six patients had acquired leprosy without leaving the country. The question of compulsory notification was raised, but was decided against in favour of attraction to leprosaria by persuasion, with the alternative of suitable domiciliary inspection by doctors and health visitors. However, as the standard of living and other conditions in Malta are different from those in England and France, I suggest that all cases of leprosy which are considered infectious and a danger to the public, should be isolated in the leper hospital.

As leprosy is an endemic disease it is highly important that its control should be centred in the hands of the Chief Medical Officer, as is the case of other endemic diseases. By the present law the control of leprosy is largely in the hands of a leprosy board, of which the Chief Government Medical Officer is not a member. Under the suggested method the existing board would not be necessary, but the Chief Medical Officer might be assisted by a small board of experts which he could convene in an advisory capacity.

(c) Educative Campaign and Survey. The third objective I would suggest is an Educative Campaign among the patients and their relatives and also the general public accompanied by a leprosy survey.

Village surveys carried out in India by expert doctors revealed the fact that for every infectious case of leprosy there were from two to four early non-infectious cases. While some of

+ Dr. Bernard informs me that $£ 900$ was paid out to families of lepers last year, and that it is proposed to increase these grants. 
these were abortive others passed on later to the infectious stage. In the Philippines, where a great deal of leprosy work had previously been done on the basis of compulsory segregation, it was believed that this finding in India was peculiar to that country. But later surveys carried out in the Philippines revealed a similar condition there. More recent surveys in Nigeria and other countries have shown that in endemic countries some such proportion of infectious and early non-infectious cases is to be expected. I consider it therefore advisable that a survey should be carried out, beginning in the areas from which the largest number of lepers have been admitted to the leper asylum. As mentioned above, this could only be done by first winning the confidence of the public in these areas.

Once the people realise that being diagnosed as a leper does not necessarily involve forcible removal to hospital, a certain amount of confidence and co-operation will be secured. Next, if local arrangements for the treatment of early and non-infectious cases are made either in a dispensary or in the people's homes, still further confidence will be gained and the tendency towards concealment from the medical authorities will be overcome.

Along with treatment, education regarding leprosy would be introduced, patients, their relatives and the public being enlightened as to the real nature of leprosy and how it can be avoided. Judging from experience elsewhere, it would probably be found that the disease is concentrated within families or comparatively small foci. It may possibly be traced back through several generations in a family or a village. Information regarding this would prove useful in persuading those concerned of the danger to themselves and their families and how it can be avoided.

In this way infectious cases could be found out by examining contacts before they spread the disease, and either isolated effectively at home or, if there are not facilities for this, or if it is considered by the medical authorities that isolation is not being carried out or likely to be carried out effectively, isolated in the hospital. The latter would be more easily accomplished on the basis that the hospital would have become a more attractive placea hive of industry in place of the present den of discontent. Also early cases could be brought under treatment, and thus in many instances prevented from advancing to the more serious and infectious stage.

(d) Staff for Educative Campaign and Village Control. The organising of such a scheme as that mentioned above would require time and experience and, above all, keen interest. It would require a number of years to bring it gradually into effect, as any attempt to rush matters would defeat the end in view. 
I understand that Dr. Naudi's services are only available for a comparatively short time. I would suggest that a qualified doctor who has had special training in India should conduct a special course on leprosy to be attended by doctors from the areas which experience has shown are leprosy foci. Later, under this officer's supervision local treatment of patients, might be carried out. The local doctors would also keep in touch with all patients and report their progress to the leprosy expert.

\section{Conclusion}

The suggestion to cancel the present leper act involves a certain amount of risk. On the other hand, the scheme suggested offers a method which has been found successful elsewhere and which holds out the hope of abolishing the present highly unsatisfactory state of things. It aims at getting down to the root of the problem which the present system clearly does not. The question arises-does the end in view justify the risk involved? My own experience leads me to believe that the scheme suggested would be successful if carried out thoroughly and completely. Its success would depend chiefly on the personnel; the placing of control in the hands of the Chief Medical Officer; the appointment of a whole-time permanent leprosy expert who would spend his time in the hospital, and another who would carry out the organising of village control through education, survey and treatment in the villages with the help of local Government doctors; and the improvement of conditions in the hospital through a suitable lay worker. The success of the scheme will, in my opinion, be endangered unless carried out in its entirety.

I believe that the British Empire Leprosy Relief Association can supply a suitable lay worker, and I understand that two suitable medical men* would be forthcoming, who, after a course of special training in India, could effectively undertake the indoor and outdoor sides of the medical work.

Acknowledgments. I wish to express my thanks especially to the Government of Malta and Dr. Bernard, the Chief Medical Officer, and also ta Dr. Naudi, for the facilities they gave me for investigation, and for all their kindness and hospitality during my visit.

* I understand that a doctor has now been appointed for this work and sent to India for training. 